\title{
Reaction of atomic hydrogen with formic acid $\dagger$
}

Cite this: Phys. Chem. Chem. Phys., 2014, 16, 5993

Received 13th December 2013, Accepted 29th January 2014

DOI: $10.1039 / c 3 c p 55265 a$

www.rsc.org/pccp

\author{
Qian Cao, ${ }^{a}$ Slawomir Berski, ${ }^{\mathrm{b}}$ Zdzislaw Latajka, ${ }^{\mathrm{b}}$ Markku Räsänen ${ }^{\mathrm{a}}$ and \\ Leonid Khriachtchev*a
}

\begin{abstract}
We study the reaction of atomic hydrogen with formic acid and characterize the radical products using IR spectroscopy in a $\mathrm{Kr}$ matrix and quantum chemical calculations. The reaction first leads to the formation of an intermediate radical trans $-\mathrm{H}_{2} \mathrm{COOH}$, which converts to the more stable radical transcis- $\mathrm{HC}(\mathrm{OH})_{2}$ via hydrogen atom tunneling on a timescale of hours at $4.3 \mathrm{~K}$. These open-shell species are observed for the first time as well as a reaction between atomic hydrogen and formic acid. The structural assignment is aided by extensive deuteration experiments and $a b$ initio calculations at the UMP2 and $\mathrm{UCCSD}(\mathrm{T})$ levels of theory. The simplest geminal diol radical trans-cis- $\mathrm{HC}(\mathrm{OH})_{2}$ identified in the present work as the final product of the reaction should be very reactive, and further reaction channels are of particular interest. These reactions and species may constitute new channels for the initiation and propagation of more complex organic species in the interstellar clouds.
\end{abstract}

\section{Introduction}

Reactions of atomic hydrogen with various molecules are fundamental in combustion, atmospheric, and interstellar chemistry as well as in biology. These reactions can occur with a variety of inorganic and organic species..$^{1-7}$ Reactions of atomic hydrogen with organic compounds, especially with hydrocarbons, have been extensively studied $;^{1-3}$ however, relatively little information is available on reactions with organic acids. A very early report on the hydrogen abstraction reaction in acetic acid $\left(\mathrm{H}+\mathrm{CH}_{3} \mathrm{COOH} \rightarrow \mathrm{CH}_{2} \mathrm{COOH}+\mathrm{H}_{2}\right)$ in aqueous solution seems to be the only experimental example of a reaction between an organic acid and atomic hydrogen. ${ }^{8}$

Formic acid (FA) is the simplest organic acid that is an important intermediate in chemical synthesis and significant in atmospheric and interstellar chemistry as well as in human metabolism. Reactions of $\mathrm{FA}$ with $\mathrm{OH}$ and $\mathrm{Cl}$ radicals have been studied, which are important sources of the hydrocarboxyl radical (HOCO) in the atmosphere. ${ }^{9}$ The reaction of $\mathrm{Cl}$ with FA was found to proceed predominantly via abstraction of the

\footnotetext{
${ }^{a}$ Department of Chemistry, University of Helsinki, P.O. Box 55, FI-00014 Helsinki, Finland. E-mail: leonid.khriachtchev@helsinki.fi; Tel: +358 919150310

${ }^{b}$ Faculty of Chemistry, University of Wroclaw, 14, F. Joliot-Curie Str., 50-383 Wroclaw, Poland

$\dagger$ Electronic supplementary information (ESI) available: The optimized geometries of the species under consideration at the UPM2 and UCCSD(T) levels of theory (Table S1), the calculated vibrational frequencies and intensities of trans$\mathrm{H}_{2} \mathrm{COOH}$, trans-cis- $\mathrm{HC}(\mathrm{OH})_{2}$ and their deuterated analogues at the UPM2 level of theory (Table S2), and the total energy for hydrogen atom transfer from trans$\mathrm{H}_{2} \mathrm{COOH}$ to trans-cis- $\mathrm{HC}(\mathrm{OH})_{2}$ along the IRC path (Fig. S1). See DOI: 10.1039/ c3cp55265a
}

hydrogen atom from the carbon atom to form HOCO rather than the abstraction of the hydroxyl hydrogen to form $\mathrm{HCO}_{2} \cdot{ }^{10,11} \mathrm{FA}$ is a model system of conformational isomerism resulting from different orientations of the $\mathrm{OH}$ group (trans and cis), ${ }^{12}$ which is typical for carboxylic acids, including amino acids. Conformational changes promoted by vibrational excitation and the backreaction via hydrogen atom tunneling have been reported for different carboxylic acids, such as FA, acetic acid, and propionic acid. $^{12-14}$ Hydrogen atom tunneling has also been recently reported for the simplest aromatic carboxylic acid, benzoic acid. ${ }^{15}$ The conformation-dependent reaction between FA and atomic oxygen was observed in $\mathrm{Kr}$ and Xe matrices. ${ }^{16}$ The FA + O reaction leads to peroxyformic acid $(\mathrm{HCOOOH})$ for the ground-state transFA conformer, and it results in the hydrogen bonded FA $\cdots \mathrm{O}$ complex for the higher-energy cis-FA conformer. ${ }^{16}$ To the best of our knowledge, no direct experimental and theoretical data are available for the reaction of FA with atomic hydrogen to date. It should be emphasized that the present work investigates the reaction of a neutral hydrogen atom with FA forming radicals. This reaction is different from FA protonation, which is a known process leading to closed-shell species.

Reactions of atomic hydrogen with organic compounds can produce radicals; for example, the hydrogen atom abstraction and molecular hydrogen formation are observed for ethane whereas the hydrogen atom addition to the unsaturated carbon atom occurs for ethylene resulting in the formation of a vibrationally excited $\mathrm{C}_{2} \mathrm{H}_{5}$ radical. ${ }^{1,2}$ Hydrogen atom transfer plays a significant role in many organic and biological reactions. In particular, the radical isomerization via intramolecular hydrogen atom transfer in species with the $\mathrm{C}-\mathrm{H}, \mathrm{O}-\mathrm{H}$, and $\mathrm{C}=\mathrm{O}$ bonds often occurs in peptide and protein radicals as a result of radiation or oxidative damage. ${ }^{17,18}$ 
It is probable that reaction of atomic hydrogen with FA produces radicals via hydrogen atom addition, which may then isomerize via intramolecular hydrogen transfer.

Matrix-isolation IR spectroscopy is a valuable method to study reactive intermediates obtained in reactions of atomic hydrogen. In our group, the $\mathrm{H}+\mathrm{C}_{2} \mathrm{H}_{2} \rightarrow \mathrm{C}_{2} \mathrm{H}_{3},{ }^{19} \mathrm{H}+\mathrm{HCN} \rightarrow$ $\mathrm{H}_{2} \mathrm{CN},{ }^{20} \mathrm{H}+\mathrm{HNCO} \rightarrow \mathrm{H}_{2} \mathrm{NCO},{ }^{21}$ and $\mathrm{H}+\mathrm{N}_{2} \mathrm{O} \rightarrow \mathrm{HN}_{2} \mathrm{O}^{22}$ reactions have been detected in rare-gas matrices, in which the hydrogen atoms are produced by photolysis of suitable precursors (e.g., $\mathrm{C}_{2} \mathrm{H}_{2}, \mathrm{HCN}, \mathrm{HNCO}$, and $\mathrm{HBr}$ ) and the formed radicals are characterized by IR spectroscopy. An interesting case is the $\mathrm{H}+\mathrm{SO}_{2}$ reaction. ${ }^{23}$ The higher-energy $\mathrm{HSO}_{2}$ isomer is formed in this reaction instead of the lower-energy isomer cis-HOSO, which is explained by a low barrier for the $\mathrm{HSO}_{2}$ formation and a high barrier for the cis-HOSO formation. $\mathrm{HSO}_{2}$ can be isomerised into cis-HOSO by visible light, one proposed mechanism of which is the direct isomerisation via intramolecular hydrogen atom transfer.

In the present work, we study the reactions of hydrogen atoms with $\mathrm{FA}$ in a $\mathrm{Kr}$ matrix and characterize the radical products using IR spectroscopy. Hydrogen (deuterium) atoms are produced by UV photolysis of $\mathrm{HBr}$ and $\mathrm{HCl}\left(\mathrm{D}_{2} \mathrm{C}_{2}\right)$. Thermal mobilization of the hydrogen atoms promotes the $\mathrm{H}+\mathrm{FA}$ reaction, leading first to the formation of an intermediate radical trans $-\mathrm{H}_{2} \mathrm{COOH}$, which converts via hydrogen atom tunneling to the more stable radical trans-cis- $\mathrm{HC}(\mathrm{OH})_{2}$. The structural assignment is aided by extensive deuteration experiments and $a b$ initio calculations at the UMP2 and UCCSD(T) levels of theory.

\section{Computational details and results}

The optimization of the geometrical structures and calculation of the relative energies and vibrational spectra were performed using the UCCSD(T) and UMP2 methods with the aug-cc-pVTZ basis set. The Molpro program was used for the UCCSD(T) calculations and Gaussian09 (version C.01) for the UMP2 calculations. The minima on the potential energy surface (PES) were verified on the basis of harmonic vibration analysis which yielded no imaginary frequencies. In the case of the transition state (TS), one imaginary frequency was obtained. The minima on the PES associated with the TS were verified by means of the intrinsic reaction coordinate (IRC) analysis. The relative energy $(\Delta E)$ between the optimized geometrical structures was corrected for the zero-point vibrational energy difference ( $\triangle \mathrm{ZPVE})$.

The reaction of a hydrogen atom with FA may proceed by three different channels: (i) reaction with the oxygen atom of the hydroxyl group $(\mathrm{OH})$, (ii) reaction with the oxygen atom of the carbonyl group $(\mathrm{C}=\mathrm{O})$, and (iii) reaction with the carbon atom. These channels have been studied by the UMP2/aug-ccpVTZ and UCCSD(T)/aug-cc-pVTZ calculations. For channel (i), no minimum was found on the PES. This process results in the formation of a new $\mathrm{H}-\mathrm{O}$ bond, the breaking of the $\mathrm{C}-\mathrm{O}$ bond and the formation of a water molecule, which finally leads to

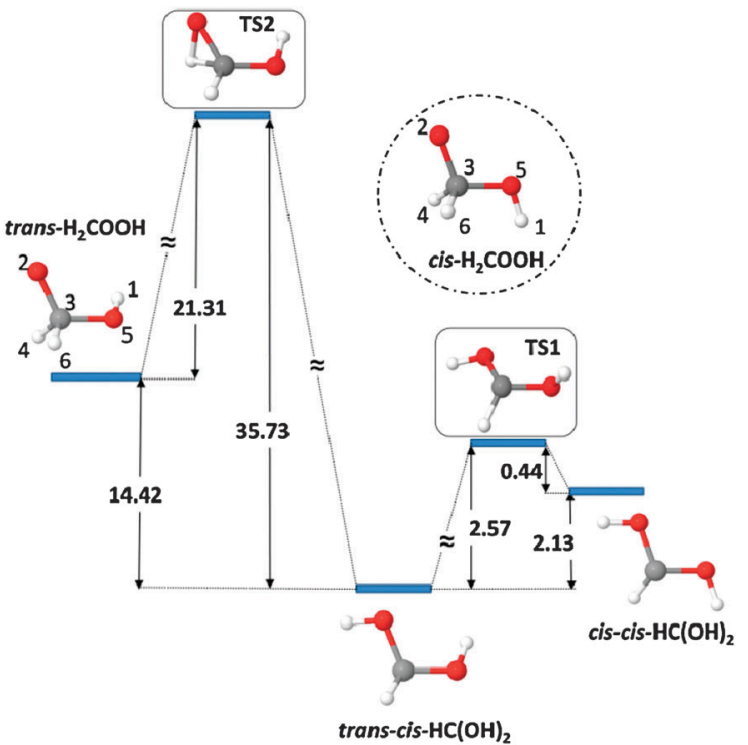

Fig. 1 Schematic potential energy diagram of the radicals that may be formed in the $\mathrm{H}+\mathrm{HCOOH}$ reaction. The energy values (in $\mathrm{kcal} \mathrm{mol}^{-1}$ ) are calculated at the UMP2 level (for the UCCSD(T) energies of the optimized structures see Table 1). The structures shown in rectangles are transition states (TS1 and TS2); $\mathrm{Cis}-\mathrm{H}_{2} \mathrm{COOH}$ (shown in a dashed circle) is energetically unfavourable. In trans $-\mathrm{H}_{2} \mathrm{COOH}, \mathrm{H} 1$ and $\mathrm{H} 4$ are on the same side of the heavy-atom skeleton.

the $\mathrm{HCO} \cdots \mathrm{H}_{2} \mathrm{O}$ complex. Two other channels produce radicals shown in Fig. 1. For channel (ii), the $\mathrm{HC}(\mathrm{OH})_{2}$ radical is formed that accepts two conformers. The two $\mathrm{O}-\mathrm{H}$ bonds can be oriented in the same direction as the $\mathrm{C}-\mathrm{H}$ bond (cis-cis form) or one $\mathrm{O}-\mathrm{H}$ bond can be oriented in the opposite direction to the $\mathrm{C}-\mathrm{H}$ bond (trans-cis form). These structures present the simplest geminal diol radicals. The trans-trans form of $\mathrm{HC}(\mathrm{OH})_{2}$ is a transition state with one imaginary frequency, which is above the trans-cis form by about $1.55 \mathrm{kcal} \mathrm{mol}^{-1}$ (UMP2). Channel (iii) leads to the $\mathrm{H}_{2} \mathrm{COOH}$ radical with two $\mathrm{C}-\mathrm{H}$ bonds and one $\mathrm{O}-\mathrm{H}$ bond which may be oriented in two directions as shown in Fig. 1. The trans conformer has an out-of-plane $\mathrm{OH}$ bond $\left(\angle \mathrm{O}-\mathrm{C}-\mathrm{O}-\mathrm{H}=56^{\circ}\right)$ and two non-equivalent $\mathrm{CH}$ bonds. The analysis shows that the cis form has practically no stabilization barrier; thus, it can be excluded from the consideration. The optimized geometries of the species under consideration are presented in Table S1, ESI. $\dagger$

The energetic effect associated with the formation of the new bonds, $\mathrm{H}-\mathrm{O}$ in $\mathrm{HC}(\mathrm{OH})_{2}$ and $\mathrm{H}-\mathrm{C}$ in $\mathrm{H}_{2} \mathrm{COOH}$, is characterized by the reaction energy $\left(\Delta E_{\mathrm{r}}\right)$ calculated for the reactions:

$$
\begin{aligned}
& \mathrm{H}+\mathrm{HCOOH} \rightarrow \mathrm{HC}(\mathrm{OH})_{2} \\
& \mathrm{H}+\mathrm{HCOOH} \rightarrow \mathrm{H}_{2} \mathrm{COOH}
\end{aligned}
$$

The value of $\Delta E_{\mathrm{r}}$ is the difference between the total energy of the $\mathrm{HC}(\mathrm{OH})_{2}$ or $\mathrm{H}_{2} \mathrm{COOH}$ radical and the sum of the total energies of the hydrogen atom and FA (the lowest energy form) corrected by $\triangle \mathrm{ZPVE}$ (see Table 1 ). The formation of the $\mathrm{HC}(\mathrm{OH})_{2}$ radical is energetically favourable for both UMP2 
Table 1 Energetics (in $\mathrm{kcal} \mathrm{mol}^{-1}$ ) for the radicals that may be formed in the $\mathrm{H}+\mathrm{HCOOH}$ reactions calculated at the UCCSD(T) and UMP2 (in parentheses) levels of theory

\begin{tabular}{llllr}
\hline & \multicolumn{2}{l}{$\begin{array}{l}\text { Relative energy } \\
(\Delta E+\Delta \mathrm{ZPVE})\end{array}$} & \multicolumn{2}{l}{$\begin{array}{l}\text { Reaction energy } \\
\left(\Delta E_{\mathrm{r}}+\Delta \mathrm{ZPVE}\right)\end{array}$} \\
\hline trans-cis- $\mathrm{HC}(\mathrm{OH})_{2}$ & 0 & $(0)$ & -10.01 & $(-10.87)$ \\
cis - cis $-\mathrm{HC}(\mathrm{OH})_{2}$ & 2.16 & $(2.13)$ & -7.85 & $(-8.74)$ \\
trans $-\mathrm{H}_{2} \mathrm{COOH}$ & 8.10 & $(14.42)$ & -1.91 & $(+3.55)$ \\
cis $-\mathrm{H}_{2} \mathrm{COOH}$ & 10.19 & $(16.61)$ & +0.17 & $(+5.74)$ \\
\end{tabular}

and UCCSD(T) computational methods with $\Delta E_{\mathrm{r}}$ of -10.87 (trans-cis), -8.74 (cis-cis) kcal $\mathrm{mol}^{-1}$ and -10.01 (trans-cis), -7.85 (cis-cis) $\mathrm{kcal} \mathrm{mol}^{-1}$, respectively. For the formation of $\mathrm{H}_{2} \mathrm{COOH}$, the UMP2 method gives positive $\Delta E_{\mathrm{r}}$ of 3.55 (trans) and 5.74 (cis) kcal $\mathrm{mol}^{-1}$. The better description of the electron correlation using the UCCSD(T) method leads to a qualitatively different result. The formation of trans $-\mathrm{H}_{2} \mathrm{COOH}$ is energetically favourable with negative $\Delta E_{\mathrm{r}}\left(-1.91 \mathrm{kcal} \mathrm{mol}^{-1}\right)$ whereas positive $\Delta E_{\mathrm{r}}\left(0.17 \mathrm{kcal} \mathrm{mol}^{-1}\right)$ is predicted for the cis form. trans $-\mathrm{H}_{2} \mathrm{COOH}$ is $14.42 \mathrm{kcal} \mathrm{mol}^{-1}$ (UMP2) and $8.10 \mathrm{kcal} \mathrm{mol}^{-1}$ (UCCSD(T)) above trans-cis- $\mathrm{HC}(\mathrm{OH})_{2}$ on the total energy scale. trans-cis- $\mathrm{HC}(\mathrm{OH})_{2}$ is lower in energy than cis-cis- $\mathrm{HC}(\mathrm{OH})_{2}$ by $2.13 \mathrm{kcal} \mathrm{mol}^{-1}$ (UMP2) and $2.16 \mathrm{kcal} \mathrm{mol}^{-1}$ (UCCSD(T)), as shown in Table 1. The isomerization from trans-cis- $\mathrm{HC}(\mathrm{OH})_{2}$ to cis-cis$\mathrm{HC}(\mathrm{OH})_{2}$ requires an activation energy $\left(E_{\mathrm{a}}\right)$ of $2.57 \mathrm{kcal} \mathrm{mol}^{-1}$ (UMP2), which is several times smaller than the activation energy of the trans-to-cis reaction of FA $\left(11.7 \mathrm{kcal} \mathrm{mol}^{-1}\right)$. The optimized geometrical structure of the transition state (TS1) is shown in Fig. 1. The conformational change from trans $-\mathrm{H}_{2} \mathrm{COOH}$ to trans cis- $\mathrm{HC}(\mathrm{OH})_{2}$ requires the transfer of the hydrogen atom from the carbon atom to the carbonyl oxygen. The energy barrier associated with this process (TS2, Fig. 1) is $21.31 \mathrm{kcal} \mathrm{mol}^{-1}$ (UMP2). The energy barrier of the opposite process is substantially higher and equals $35.73 \mathrm{kcal} \mathrm{mol}^{-1}$ (UMP2). The change in the total energy for hydrogen atom transfer from trans- $\mathrm{H}_{2} \mathrm{COOH}$ to trans-cis- $\mathrm{HC}(\mathrm{OH})_{2}$ along the IRC path is shown in Fig. S1 (ESI $\dagger$ ).

The characteristic frequencies of the proposed radicals and their deuterated analogues obtained at the UCCSD(T)/aug-ccpVTZ level of theory are presented in Table 2. The full spectra at the UMP2/aug-cc-pVTZ levels are presented in Table S2, ESI. $\dagger$

\section{Experimental details and results}

Formic acid $\mathrm{HCOOH}$ (99\%, Kebo Lab) and its deuterated analogues DCOOH (99\%, Icon Isotopes) and HCOOD (95\%, IT Isotop) were degassed by several freeze-pump-thaw cycles. The FA/HY/Kr (1/2/1000) $(\mathrm{Y}=\mathrm{Br}, \mathrm{Cl})$ and $\mathrm{FA} / \mathrm{C}_{2} \mathrm{D}_{2} / \mathrm{Kr}(1 / 2 / 1000)$ matrices $\left(\mathrm{HBr}, \geq 99 \%\right.$, Aldrich; $\mathrm{HCl}, \geq 99 \%$, Linde; $\mathrm{C}_{2} \mathrm{D}_{2}$, $\geq 98 \%$, Cambridge Isotope Laboratories; $\mathrm{Kr}, \geq 99.999 \%$, AGA) were deposited onto a CsI window at $20 \mathrm{~K}$ in a closed cycle helium cryostat (RDK 408D, Sumitomo Heavy Industries). The IR spectra were recorded in the spectral region $4000-500 \mathrm{~cm}^{-1}$ at $4.3 \mathrm{~K}$ using a Bruker VERTEX 80 FTIR spectrometer typically using 200 scans and a resolution of $0.5 \mathrm{~cm}^{-1}$. The solid matrices were photolyzed at $4.3 \mathrm{~K}$ using an ArF excimer laser
(193 nm, MSX-250, MPB) to produce H or D atoms, typically using 1500 pulses (pulse energy density $\sim 12 \mathrm{~mJ} \mathrm{~cm}^{-2}$ and pulse duration $\sim 10 \mathrm{~ns}$ ). Vibrational excitation was promoted using an optical parametric oscillator (OPO Sunlite, Continuum with IR extension) providing tunable IR light with a pulse duration of $\sim 5 \mathrm{~ns}$, linewidth of $\sim 0.1 \mathrm{~cm}^{-1}$, and repetition rate of $10 \mathrm{~Hz}$. A Burleigh WA-4500 wavemeter measured the OPO signal frequency, providing an absolute accuracy better than $1 \mathrm{~cm}^{-1}$ for the IR light.

The vibrational spectra of the ground-state (trans) conformer of $\mathrm{HCOOH}, \mathrm{DCOOH}$, and HCOOD in a Kr matrix recorded in our experiments agree well with the literature. ${ }^{24,25} 193 \mathrm{~nm}$ photolysis (1500 pulses) of a $\mathrm{HCOOH} / \mathrm{HBr} / \mathrm{Kr}(1 / 2 / 1000)$ matrix decomposes about $85 \% \mathrm{HBr}$, producing $\mathrm{H}$ and $\mathrm{Br}$ atoms. About $30 \% \mathrm{FA}$ is also decomposed producing mainly the $\mathrm{CO} \cdots \mathrm{H}_{2} \mathrm{O}$ complex. ${ }^{24}$

Annealing of a photolyzed $\mathrm{HCOOH} / \mathrm{HBr} / \mathrm{Kr}$ matrix at $31 \mathrm{~K}$ mobilizes hydrogen atoms in a $\mathrm{Kr}$ matrix, ${ }^{26}$ which leads to the formation of new absorption bands (trace 1 in Fig. 2). Annealing of the photolyzed matrices also leads to a loss of FA. Fig. 3 shows that the amount of the products after annealing increases with the corresponding loss of FA.

The new absorption bands can be separated into two products marked by $\mathbf{I}_{\mathrm{U}}$ and $\mathbf{I}_{\mathrm{S}}$ (labels $\mathrm{U}$ and $\mathrm{S}$ indicate unstable and stable, respectively). Immediately after annealing, product $\mathbf{I}_{U}$ dominates over product $\mathbf{I}_{\mathrm{S}}$. The bands of product $\mathbf{I}_{\mathrm{U}}$ slowly decrease in intensity in the dark whereas the bands of product $\mathbf{I}_{\mathrm{S}}$ rise (trace 1 in Fig. 4). This process is accelerated by broad band IR light of the spectrometer (trace 2 in Fig. 2). In both cases, the amounts of $\mathbf{I}_{U}$ and $\mathbf{I}_{S}$ change with the same rates. The amount of $\mathbf{I}_{U}$ goes to zero and the amount of $\mathbf{I}_{S}$ tends to saturate. These facts feature the $\mathbf{I}_{U}$-to- $^{-} \mathbf{I}_{S}$ conversion. This conversion process is also accelerated by vibrational excitation of product $\mathbf{I}_{U}$ at $3614 \mathrm{~cm}^{-1}$ by the OPO (trace 3 in Fig. 2) whereas the vibrational excitation of product $\mathbf{I}_{\mathrm{S}}$ (at 3636.0 and $3598.4 \mathrm{~cm}^{-1}$ ) does not lead to the opposite process. The same two products are observed after photolysis and annealing of $\mathrm{HCOOH} / \mathrm{HCl} / \mathrm{Kr}$ matrices (trace 4 in Fig. 2).

It is noted that several bands of the products are split, which is probably due to trapping of the molecules in different matrix sites. The sub-bands of product $\mathbf{I}_{U}$ are bleached with different efficiencies when exposed to narrow-band IR light. For excitation at about $3614 \mathrm{~cm}^{-1}$, the band at $3613.7 \mathrm{~cm}^{-1}$ is efficiently bleached together with the bands at 1116.0 and $962.0 \mathrm{~cm}^{-1}$. In contrast, the decrease of the bands at 3615.0, 1115.1, and $964.5 \mathrm{~cm}^{-1}$ is much less efficient for excitation at about $3615 \mathrm{~cm}^{-1}$.

The experiments with deuterated species were also performed under the same experimental conditions. Annealing of a photolyzed $\mathrm{HCOOD} / \mathrm{HBr} / \mathrm{Kr}$ matrix initially leads to product $\mathbf{I}_{\mathrm{U}}$ that then converts in the dark to two products $\mathbf{I I}_{\mathrm{S}}$ and $\mathbf{I I}_{\mathrm{S}}{ }^{\prime}$ (trace 2 in Fig. 4, see discussion below). It should be noted that FA in this matrix is, due to incomplete deuteration, a mixture of $\mathrm{HCOOD}$ and $\mathrm{HCOOH}$ (70/30), which explains the formation of some amount of products $\mathbf{I}_{\mathrm{U}}$ and $\mathbf{I}_{\mathrm{S}}$. In trace 2, the bands of these products are subtracted. Most indicative, the new characteristic bands are observed in the OD stretching region (2690-2650 $\mathrm{cm}^{-1}$ ), which are absent 
Table 2 Experimental $\left(\mathbf{I}_{\cup}-\mathrm{III}_{\cup}\right.$ and $\left.\mathbf{I}_{\mathrm{S}}-\mathrm{III}_{\mathrm{S}}\right)$ and calculated characteristic bands of trans $-\mathrm{H}_{2} \mathrm{COOH}$ and trans-Cis- $\mathrm{HC}(\mathrm{OH})_{2}$ and their deuterated analogues $^{a}$

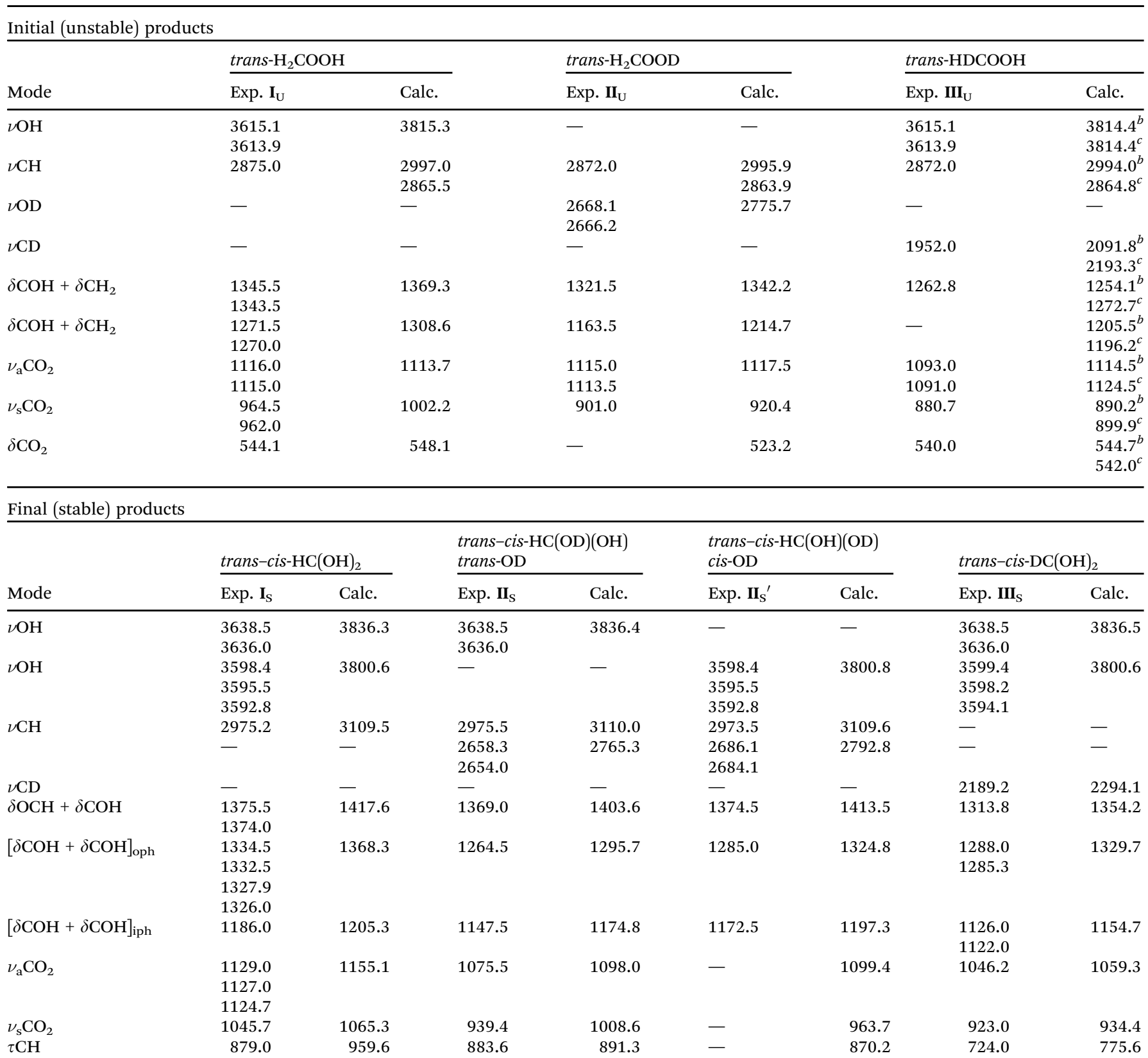

${ }^{a}$ Calculations at the UCCSD(T) level of theory. ${ }^{b}$ trans-HDCOOH with $\mathrm{CD}$ deuteration in position 4 (see Fig. 1 ). ${ }^{c}$ trans-HDCOOH with $\mathrm{CD}$ deuteration in position 6 (see Fig. 1).

in the case of $\mathrm{HCOOH} / \mathrm{HBr} / \mathrm{Kr}$ matrices (trace 1 in Fig. 4). Additional new strong bands are observed at 1180-1140 $\mathrm{cm}^{-1}$ and $901 \mathrm{~cm}^{-1}$.

Annealing of a photolyzed $\mathrm{DCOOH} / \mathrm{HBr} / \mathrm{Kr}$ matrix leads to product III $_{\mathbf{U}}$ which converts in the dark to III $_{\mathbf{S}}$ (trace 3 in Fig. 4). No bands appear in this case in the OD stretching region whereas the CD stretching bands are observed for both stable and unstable products (2189.2 and $1952.0 \mathrm{~cm}^{-1}$, respectively). The most characteristic bands are observed at $1288 / 1285 \mathrm{~cm}^{-1}$ for III $_{\mathrm{S}}$ and at $1093 / 1091 \mathrm{~cm}^{-1}$ for $\mathbf{I I I}_{\mathrm{U}}$. The same characteristic features are detected in a $\mathrm{HCOOH} / \mathrm{C}_{2} \mathrm{D}_{2} / \mathrm{Kr}$ matrix, however, in quite small amounts presumably due to the relatively low efficiency of the $\mathrm{C}_{2} \mathrm{D}_{2}$ photolysis. The formation of DKrCCD $\left(920 \mathrm{~cm}^{-1}\right)^{27}$ confirms the presence and mobility of $\mathrm{D}$ atoms in the matrix. In the $\mathrm{HCOOH} / \mathrm{C}_{2} \mathrm{D}_{2} / \mathrm{Kr}$ case, the products formed in $\mathrm{HCOOH} /$ $\mathrm{HBr} / \mathrm{Kr}$ matrices are also observed and subtracted in trace 4 . The formation of these background products is explained by the presence of $\mathrm{H}$ atoms probably produced by photolysis of the $\mathrm{CO} \cdots \mathrm{H}_{2} \mathrm{O}$ complex, which is a photodecomposition product of $\mathrm{FA}^{24}$ The presence of hydrogen atoms in the matrix is evidenced by the formation of HDCCD radicals ( $c a .1220$ and $795 \mathrm{~cm}^{-1}$ ) originated from the $\mathrm{H}+$ DCCD reaction. ${ }^{19}$ In the deuteration 


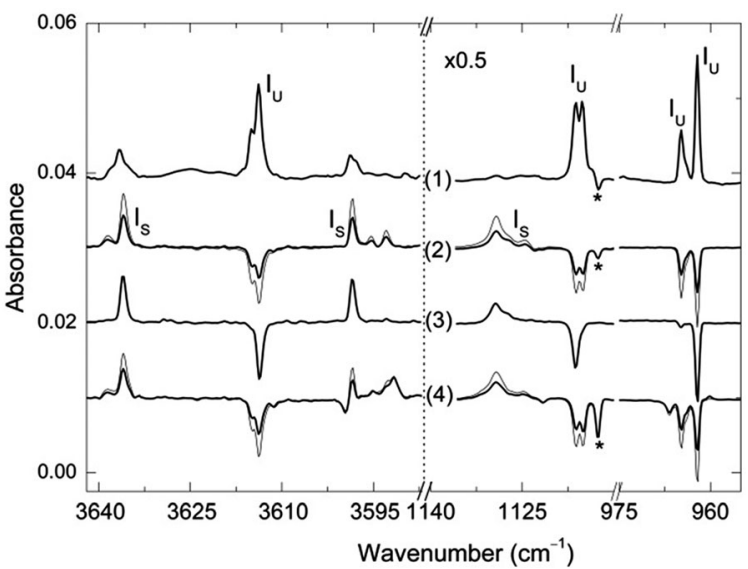

Fig. 2 Difference FTIR spectra of a $\mathrm{HCOOH} / \mathrm{HBr} / \mathrm{Kr}(1 / 2 / 1000)$ matrix photolyzed at $193 \mathrm{~nm}$ showing the results of (1) annealing at $31 \mathrm{~K}(5 \mathrm{~min})$; (2) 1 hours (thick line) and 2 hours (thin line) at $4.3 \mathrm{~K}$ under Globar irradiation after annealing; (3) narrow-band IR excitation at ca. $3614 \mathrm{~cm}^{-1}$ of the annealed matrix. Trace 4 shows the difference IR spectra of a photolyzed and annealed $\mathrm{HCOOH} / \mathrm{HCl} / \mathrm{Kr}(1 / 2 / 1000)$ matrix as a result of 1 hour (thick line) and 2 hours (thin line) at $4.3 \mathrm{~K}$ under Globar irradiation. The spectra were recorded at $4.3 \mathrm{~K}$. The bands marked by asterisks are tentatively assigned to a FA dimer (tt4). ${ }^{39}$

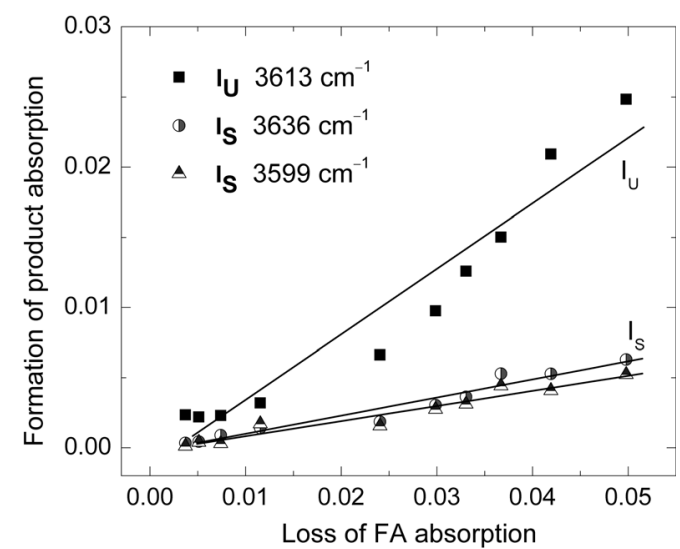

Fig. 3 Amount of products $I_{\cup}$ and $I_{S}$ versus the corresponding loss of FA $\left(3536.5 \mathrm{~cm}^{-1}\right)$ in the $\mathrm{H}+\mathrm{FA}$ reaction. The spectra were recorded at $4.3 \mathrm{~K}$ immediately after annealing at $31 \mathrm{~K}$ of a photolyzed $\mathrm{HCOOH} / \mathrm{HBr} / \mathrm{Kr}(1 / 2)$ 1000) matrix. The data points correspond to the integrated intensities of the absorption bands in different experiments. The lines are linear fits.

experiments, the band intensities of the products correlate well with the annealing-induced loss of FA.

The decay of the initial products in the dark and the formation of the final products have similar rates independent of deuteration described above (characteristic time $\sim 7.5$ hours at $4.3 \mathrm{~K}$, Fig. 5). The conversion is accelerated at elevated temperatures (characteristic time $\sim 5.0$ hours at $27 \mathrm{~K}$ ). The sum of the relative intensities of the decreasing and rising bands does not change in time. The situation is absolutely different for a $\mathrm{DCOOH} / \mathrm{C}_{2} \mathrm{D}_{2} / \mathrm{Kr}$ matrix. In this case, an annealing-induced band is observed at $3616.6 \mathrm{~cm}^{-1}$, which is the OH stretching mode of the "unstable" product; however, this band does not decrease in the dark even in 45 hours. The decay of this band can be promoted by broadband light of the spectrometer.
The weakness of the bands in this experiment prevents a detailed analysis in other spectral regions.

\section{Discussion}

\section{Spectral assignments}

The new products appear as a result of annealing at temperatures that mobilize hydrogen atoms in a $\mathrm{Kr}$ matrix. ${ }^{26}$ It follows that the initial (unstable) product most probably originates from reactions of mobile hydrogen atoms with another fragment. For the assignment, several possibilities have been considered. First of all, the $\mathrm{CO} \cdots \mathrm{H}_{2} \mathrm{O}$ complex is present in the matrix as a result of the decomposition of FA. ${ }^{24}$ Mobile hydrogen atoms can react with this complex producing the $\mathrm{HCO} \cdots \mathrm{H}_{2} \mathrm{O}$ complex, and this possibility should be discussed. In fact, the $\mathrm{HCO} \cdots \mathrm{H}_{2} \mathrm{O}$ complex obtained from the $\mathrm{H}+\mathrm{CO} \cdots \mathrm{H}_{2} \mathrm{O}$ reaction has been recently identified by us, ${ }^{28}$ and it is also observed in the present work. The formation of the $\mathrm{HCO} \cdots \mathrm{H}_{2} \mathrm{O}$ complex is the most efficient when FA is mostly decomposed, i.e. when the amount of the $\mathrm{CO} \cdots \mathrm{H}_{2} \mathrm{O}$ complex is large. As expected, the bands of the $\mathrm{HCO} \cdots \mathrm{H}_{2} \mathrm{O}$ complex do not change in the dark, in contrast to the new products studied in the present work. The spectra of these products differ significantly from that of the $\mathrm{HCO} \cdots \mathrm{H}_{2} \mathrm{O}$ complex. For example, the $\mathrm{HCO} \cdots \mathrm{H}_{2} \mathrm{O}$ complex in a $\mathrm{Kr}$ matrix has a strong CO stretching band at $1853.3 \mathrm{~cm}^{-1}$. $^{28}$

The correlation between the amount of the products and the loss of FA (Fig. 3) strongly suggests that the new species originate from the $\mathrm{H}+\mathrm{FA}$ reaction. The small deviation from the exact proportionality can be caused, for example, by the annealinginduced formation of FA dimers and by the consumption of hydrogen atoms in reactions with $\mathrm{HBr}$. In principle, the $\mathrm{H}+\mathrm{FA}$ reaction can lead to the formation of a $\mathrm{H}_{2}$ molecule and a radical species via $\mathrm{H}$ abstraction. However, the possible radicals cannot simultaneously have the $\mathrm{OH}$ and $\mathrm{CH}$ stretching modes, which rules out this scenario.

The addition of a hydrogen atom to different positions in FA should also be considered. For example, a hydrogen atom may react with the oxygen atom of the $\mathrm{OH}$ group forming $\mathrm{HCOOH}_{2}$. Our calculations suggest that this species is not an energy minimum, and it spontaneously decomposes to a pair of $\mathrm{H}_{2} \mathrm{O}$ and HCO. Thus, this reaction (if occurred) would lead to the formation of the $\mathrm{HCO} \cdots \mathrm{H}_{2} \mathrm{O}$ complex in a matrix.

The addition of a hydrogen atom to the oxygen atom of the $\mathrm{C}=\mathrm{O}$ group is also possible, which would result in the $\mathrm{HC}(\mathrm{OH})_{2}$ radical. The calculations show that the $\mathrm{HC}(\mathrm{OH})_{2}$ radical has two local minima differing by the orientation of the $\mathrm{OH}$ groups, the higher-energy cis-cis form and the lower-energy trans-cis form (Fig. 1). Similar conformers exist for carbonic acid, although the energetics is opposite, with the cis-cis form being more stable than the trans-cis form (by 1.0-1.6 kcal mol${ }^{-1}$ ). ${ }^{29,30}$ Both of these conformers of carbonic acid have been observed in an $\mathrm{Ar}$ matrix. ${ }^{29}$ For this reason, we have to consider the initial formation of cis-cis- $\mathrm{HC}(\mathrm{OH})_{2}$ which converts to trans-cis$\mathrm{HC}(\mathrm{OH})_{2}$. However, the calculated barrier between these two species is only $0.44 \mathrm{kcal} \mathrm{mol}^{-1}$, which is much smaller than 

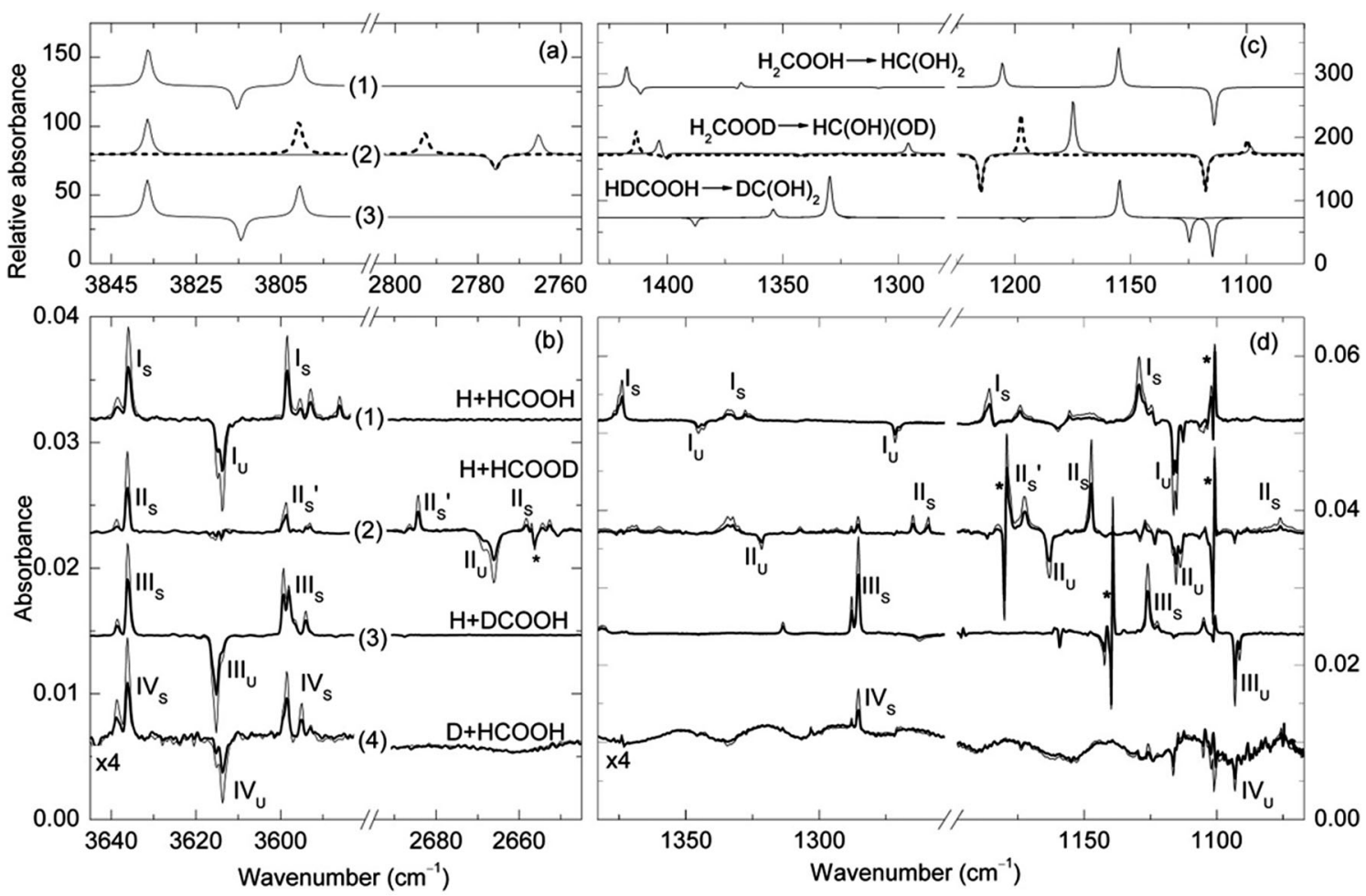

Fig. 4 (a and c) Calculated IR spectra of trans $-\mathrm{H}_{2} \mathrm{COOH}$ (negative bands) and trans-cis- $\mathrm{HC}(\mathrm{OH})_{2}$ (positive bands) and their deuterated analogues. The dashed line in the calculated spectrum (2) corresponds to trans-cis-HC(OH)(OD) with the cis-OD group. The splitting of the negative band in the calculated spectrum (3) of trans- $\mathrm{HDCOOH}$ is caused by different locations of the $\mathrm{CD}$ group. (b and d) Difference IR spectra showing the conversion processes after different reactions: (1) $\mathrm{H}+\mathrm{HCOOH}$, (2) $\mathrm{H}+\mathrm{HCOOD},(3) \mathrm{H}+\mathrm{DCOOH}$, and (4) $\mathrm{D}+\mathrm{HCOOH}$. Thick and thin lines in the experimental spectra correspond to 4 and 8 hours in the dark at $4.3 \mathrm{~K}$ after annealing, respectively. Bands of $\mathrm{FA}$ are marked by asterisks. The $\mathrm{FA} / \mathrm{HBr}\left(\mathrm{C}_{2} \mathrm{D}_{2}\right) / \mathrm{Kr}$ matrices were first photolyzed at $193 \mathrm{~nm}$ and then annealed for $5 \mathrm{~min}$ at $31 \mathrm{~K}$. The spectra were recorded at $4.3 \mathrm{~K}$. Note the different absorbance scales in the left and right panels.

that of carbonic acid $\left(9.2 \mathrm{kcal} \mathrm{mol}^{-1}\right)^{30}$ and definitely too small to stabilize the higher-energy conformer at the timescale of hours. For comparison, the cis form of FA converts to trans-FA much faster than in the present study despite the calculated stabilization barrier of $7.7 \mathrm{kcal} \mathrm{mol}^{-1}$. The exclusion of the assignment of $\mathbf{I}_{\mathrm{U}}$ to cis-cis-HC(OH$)_{2}$ is confirmed by the deuteration experiments. In particular, no OD stretching band is seen as a result of the $\mathrm{D}+\mathrm{HCOOH}$ reaction (see trace 4 in Fig. 4).

After these exclusions, the most probable mechanism of the $\mathrm{H}+\mathrm{FA}$ reaction is the addition of the hydrogen atom to the carbon atom, which results in the $\mathrm{H}_{2} \mathrm{COOH}$ radical. For this radical, only one true minimum, the trans conformer, is found, and its total energy is higher than that of trans-cis- $\mathrm{HC}(\mathrm{OH})_{2}$ by $8.10 \mathrm{kcal} \mathrm{mol}^{-1}$ (UCCSD(T)). Thus, we assign the decreasing bands to the trans $-\mathrm{H}_{2} \mathrm{COOH}$ radical and the rising bands to the trans-cis- $\mathrm{HC}(\mathrm{OH})_{2}$ radical. Our spectroscopic data show that the trans $-\mathrm{H}_{2} \mathrm{COOH}$ radical dominates immediately after annealing (trace 1 in Fig. 2 and Fig. 3 and 5) and then it slowly converts to trans-cis- $\mathrm{HC}(\mathrm{OH})_{2}$.

The amount of hydrogen atoms in the $193 \mathrm{~nm}$ irradiated $\mathrm{HCOOH} / \mathrm{HBr} / \mathrm{Kr}(1 / 2 / 1000)$ matrix is roughly twice as much as the amount of remaining FA molecules. It follows that the initial product of the $\mathrm{H}+\mathrm{FA}$ reaction $\left(\right.$ trans $\left.-\mathrm{H}_{2} \mathrm{COOH}\right)$ may in principle react with a second hydrogen atom to form the closedshell species $\mathrm{CH}_{2}(\mathrm{OH})_{2}$ (methanediol). This molecule has been observed in an Ar matrix and its vibrational spectrum is different from the spectra of our species. ${ }^{31}$ For example, the strong CO stretching band of $\mathrm{CH}_{2}(\mathrm{OH})_{2}$ is not detected in the present experiments.

Now, we analyse the spectra of the reaction products (Table 2). The $\mathrm{OH}$ stretching region is very informative. In theory, the trans-cis- $\mathrm{HC}(\mathrm{OH})_{2}$ radical has two $\mathrm{OH}$ stretching bands of similar intensity separated by about $33 \mathrm{~cm}^{-1}$ whereas the trans $-\mathrm{H}_{2} \mathrm{COOH}$ radical has one intense band located between the trans-cis- $\mathrm{HC}(\mathrm{OH})_{2}$ bands. These calculations are in perfect agreement with the experiment. In the $\mathrm{H}+\mathrm{HCOOH}$ experiment, product $\mathbf{I}_{\mathrm{S}}$ has two bands separated by $39 \mathrm{~cm}^{-1}$ and product $\mathbf{I}_{\mathrm{U}}$ has one $\mathrm{OH}$ stretching band located in between. In contrast, the calculated cis-cis- $\mathrm{HC}(\mathrm{OH})_{2}$ radical has the $\mathrm{OH}$ stretching band higher in frequency than the two bands of trans-cis- $\mathrm{HC}(\mathrm{OH})_{2}$, which also supports our assignment of the initial product to trans $-\mathrm{H}_{2} \mathrm{COOH}$.

For the $\mathrm{H}+\mathrm{HCOOD}$ reaction, the $\mathrm{OH}$ stretching region exhibits similar rising bands as in the $\mathrm{H}+\mathrm{HCOOH}$ case whereas no decreasing band appears in between. This fact strongly confirms that the unstable product is $\mathrm{H}_{2} \mathrm{COOD}$ that has no $\mathrm{OH}$ stretching mode but only $\mathrm{OD}$. The two rising bands 


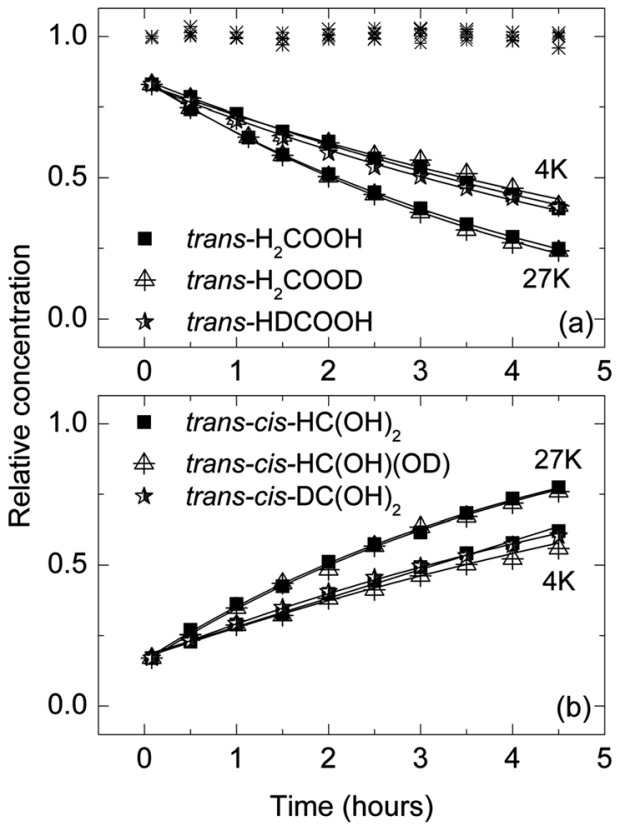

Fig. 5 Relative concentrations of the products as a function of time at different temperatures in the dark. (a) The decay of the initial products trans $-\mathrm{H}_{2} \mathrm{COOH}\left(3614 \mathrm{~cm}^{-1}\right)$, trans $-\mathrm{H}_{2} \mathrm{COOD}\left(2666 \mathrm{~cm}^{-1}\right)$, and trans$\mathrm{HDCOOH}\left(3614 \mathrm{~cm}^{-1}\right)$; (b) The formation of the final products transcis- $\mathrm{HC}(\mathrm{OH})_{2}\left(3636 \mathrm{~cm}^{-1}\right)$, trans-cis- $\mathrm{HC}(\mathrm{OH})(\mathrm{OD})\left(2684 \mathrm{~cm}^{-1}\right)$, and transcis-DC $(\mathrm{OH})_{2}\left(3636 \mathrm{~cm}^{-1}\right)$. The sum of the relative concentrations of the unstable and stable products is shown by stars in panel a.

in the OD stretching region are separated by $26 \mathrm{~cm}^{-1}$ and the decreasing band appears in between (trace 2 in Fig. 4b). The appearance of four (not two) rising bands is explained by the fact that the trans-cis- $\mathrm{HC}(\mathrm{OH})(\mathrm{OD})$ radical has two isotopic analogues. In this case, the bands at 3635 and $2658 / 2654 \mathrm{~cm}^{-1}$ are assigned to the species with the cis-OH and trans-OD groups. The second isotopic analogue has the trans-OH and cis-OD groups, absorbing at 3598 and $2686 / 2684 \mathrm{~cm}^{-1}$, respectively.

For the $\mathrm{H}+\mathrm{DCOOH}$ and $\mathrm{D}+\mathrm{HCOOH}$ reactions, the $\mathrm{OH}$ stretching bands (traces 3 and 4 in Fig. 4) are similar to the $\mathrm{H}+$ $\mathrm{HCOOH}$ case for both initial and final products (trace 1). An important observation is the absence of the OD stretching bands in these two cases, which indicates that the $\mathrm{H}$ (not D) atom is involved in the conversion process (see also later). For the $\mathrm{D}+\mathrm{HCOOH}$ reaction, the lack of the OD stretching absorption provides an additional support that the initial product is formed by the addition of a D atom to the carbon atom of FA rather than to the oxygen atom.

In the $\nu \mathrm{CH}$ and $\nu \mathrm{CD}$ regions, weak but characteristic bands are observed. For the $\mathrm{H}+\mathrm{HCOOH}$ and $\mathrm{H}+\mathrm{HCOOD}$ reactions, both products absorb in the $\mathrm{CH}$ stretching region (3100-2800 $\mathrm{cm}^{-1}$ ) whereas the CD stretching region (2300-2000 $\mathrm{cm}^{-1}$ ) shows no bands. For the $\mathrm{H}+\mathrm{DCOOH}$ reaction, the initial product exhibits the $\mathrm{CH}$ and $\mathrm{CD}$ stretching bands at 2872.0 and $1952.0 \mathrm{~cm}^{-1}$, which further confirm the addition of a hydrogen atom to the carbon atom of FA.

The spectrum in the deformation region $\left(1400-900 \mathrm{~cm}^{-1}\right)$ also supports the proposed assignment. For the $\mathrm{H}+\mathrm{HCOOH}$ reaction, the positions of the two decaying $(\sim 1116.0 / 1115.0$ and $\left.964.5 / 962.0 \mathrm{~cm}^{-1}\right)$ and three rising bands $(\sim 1326,1186.0$, and $\sim 1129 \mathrm{~cm}^{-1}$ ) are in good agreement with the calculations (1113.7 and $1002.2 \mathrm{~cm}^{-1}$ for trans $-\mathrm{H}_{2} \mathrm{COOH} ; 1368.3,1205.3$, and $1155.1 \mathrm{~cm}^{-1}$ for trans-cis- $\left.\mathrm{HC}(\mathrm{OH})_{2}\right)$. For the $\mathrm{H}+\mathrm{HCOOD}$ reaction, the spectrum significantly changes in qualitative agreement with the calculations. An intense band at $1288 \mathrm{~cm}^{-1}$ is observed for the final product for the $\mathrm{H}+\mathrm{DCOOH}$ and $\mathrm{D}+\mathrm{HCOOH}$ reactions but it is absent in other cases. According to the calculations, this band is characteristic of trans-cis-DC(OH $)_{2}$ (calculated frequency $1329.7 \mathrm{~cm}^{-1}$ ). It should be admitted that some of the experimental shifts in this region are not accurately predicted. An example is the order of two rising bands and one decaying band observed in the $\mathrm{H}+\mathrm{HCOOD}$ reaction at around $1150 \mathrm{~cm}^{-1}$. In the experiment, the decaying band is between the two rising bands whereas the calculations predict it at a higher frequency. We connect this small discrepancy with the difficulties to describe open-shell species even at the $\operatorname{UCCSD}(\mathrm{T})$ level of theory. Very accurate calculations of vibrational spectra of open-shell species require special approaches, ${ }^{32}$ but this exceeds the scope of the present work. Furthermore, this is not a surprise that some band intensities are not accurately predicted by the MP2 calculations.

\section{Formation of the radicals and intramolecular hydrogen atom transfer}

As shown above, new radicals trans $-\mathrm{H}_{2} \mathrm{COOH}$ and trans-cis$\mathrm{HC}(\mathrm{OH})_{2}$ are formed in the $\mathrm{H}+$ FA reaction. Our spectroscopic data in a $\mathrm{Kr}$ matrix suggest that this reaction primarily produces the trans $-\mathrm{H}_{2} \mathrm{COOH}$ radical by the addition of a hydrogen atom to the carbon atom of FA and this species dominates immediately after annealing. The formation of the trans$\mathrm{H}_{2} \mathrm{COOH}$ radical in the $\mathrm{H}+\mathrm{FA}$ reaction is energetically favourable (by $1.91 \mathrm{kcal} \mathrm{mol}^{-1}$ ) at the UCCSD(T) level of theory. This radical is higher in energy than the lowest-energy trans-cis$\mathrm{HC}(\mathrm{OH})_{2}$ species by $8.10 \mathrm{kcal} \mathrm{mol}^{-1}$ (UCCSD(T)). The situation when a reaction produces a metastable isomer is not unique to matrix-isolation studies. One example is the efficient formation of the higher-energy dimers of FA after deposition of matrices under some conditions. ${ }^{33}$ As another example, the $\mathrm{H}+\mathrm{SO}_{2}$ reaction mainly leads to a higher-energy isomer $\mathrm{HSO}_{2}$ but not to the ground-state isomer HOSO. ${ }^{23}$

The experimental results show that the initial product trans$\mathrm{H}_{2} \mathrm{COOH}$ converts to the trans-cis- $\mathrm{HC}(\mathrm{OH})_{2}$ radical in the dark at cryogenic temperature $(4.3 \mathrm{~K})$. We explain this isomerization process by intramolecular hydrogen-atom tunneling from carbon to oxygen atom. This process agrees with the calculated energetics of the system showing that the trans $-\mathrm{H}_{2} \mathrm{COOH}$ radical is higher in energy than the trans-cis- $\mathrm{HC}(\mathrm{OH})_{2}$. The trans $-\mathrm{H}_{2} \mathrm{COOH}$ stabilization barrier is high enough $\left(21.31 \mathrm{kcal} \mathrm{mol}^{-1}\right.$ at the UMP2 level of theory) to prevent the over-barrier process at low temperatures; however, quantum tunneling of a hydrogen atom is possible through this barrier. The tunneling mechanism is supported by the strong H/D isotope effect: (i) no OD stretching bands appear as a result of the conversion of $\mathrm{HDCOOH}$ and (ii) $\mathrm{D}_{2} \mathrm{COOH}$ is practically stable. The strong $\mathrm{H} / \mathrm{D}$ isotope effect has been repeatedly shown for quantum tunneling. ${ }^{34,35}$ 
The cis-cis- $\mathrm{HC}(\mathrm{OH})_{2}$ radical can be formed in this tunneling process but quickly decays to the trans-cis conformer due to the very low stabilization barrier $\left(0.44 \mathrm{kcal} \mathrm{mol}^{-1}\right)$. It has been recently reported that methylhydroxycarbene $\left(\mathrm{H}_{3} \mathrm{C}-\mathrm{C}-\mathrm{OH}\right)$ isomerizes to acetaldehyde $\left(\mathrm{H}_{3} \mathrm{C}-\mathrm{CH}=\mathrm{O}\right)$ with a lifetime $c a$. 1 hour in an Ar matrix at $11 \mathrm{~K}$, and the process was explained by a facile hydrogen tunneling through a barrier of $28.0 \mathrm{kcal} \mathrm{mol}^{-1} \cdot{ }^{36}$

The isomerization from trans $-\mathrm{H}_{2} \mathrm{COOH}$ to trans-cis- $\mathrm{HC}(\mathrm{OH})_{2}$ is accelerated by vibrational excitation of $\nu \mathrm{OH}$ fundamental by the narrow-band IR light but the opposite process does not occur. This fact fully agrees with the computational energies showing a significantly higher isomerization barrier (35.73 kcal mol${ }^{-1}$ ) for the opposite process. It should be noted that the photon energy (3536 $\mathrm{cm}^{-1}$ or $10.1 \mathrm{kcal} \mathrm{mol}^{-1}$ ) is smaller than the calculated stabilization barrier of trans $-\mathrm{H}_{2} \mathrm{COOH}$; however, light-induced under-barrier tunneling was demonstrated. ${ }^{37}$ The conversion process is accelerated by broad-band IR light even for $\mathrm{D}_{2} \mathrm{COOH}$, which is probably contributed by an over-barrier isomerization. Furthermore, this hydrogen-atom tunneling mechanism is consistent with the acceleration of the conversion process at elevated temperatures ( $c a .7 .5$ hours at $4 \mathrm{~K}$ and 5.0 hours at $27 \mathrm{~K}$ ), which is typical for quantum tunneling. ${ }^{34,35}$

Radical isomerization via hydrogen atom tunneling can compete with radical decomposition. In the present case, the possible decomposition channel would lead to $\mathrm{H}_{2}+\mathrm{COOH}$ (or HOCO). However, no evidence of these species is provided by the experiments as mentioned above. Another remarkable fact is that the present situation is quite different from the $\mathrm{Cl}+\mathrm{FA}$ reaction leading to $\mathrm{HCl} .{ }^{9}$ It can also be noted that the weak trans-cis- $\mathrm{HC}(\mathrm{OH})_{2}$ bands are seen immediately after annealing (trace 1 in Fig. 2). This observation seemingly suggests that some amount of this species is formed directly in the $\mathrm{H}+\mathrm{FA}$ reaction. However, more probably, these weak bands appear due to the isomerization during the annealing and the first measurement.

\section{Conclusions}

This work presents the first report on the reaction of atomic hydrogen with formic acid. The experiments in a $\mathrm{Kr}$ matrix show that this reaction proceeds via addition of the hydrogen atom to the carbon atom of FA to form the trans $-\mathrm{H}_{2} \mathrm{COOH}$ radical as the initial product. The trans $-\mathrm{H}_{2} \mathrm{COOH}$ radical isomerizes via intramolecular hydrogen atom tunneling to the lower-energy trans-cis- $\mathrm{HC}(\mathrm{OH})_{2}$ radical, which is the simplest geminal diol radical. These two radicals are directly observed for the first time and characterized by using IR spectroscopy and $a b$ initio calculations at the UMP2 and UCCST(T) levels of theory. The assignment of the products and the hydrogen atom tunneling mechanism of the isomerization are confirmed by experiments with deuterated species.

The simplest geminal diol radical trans-cis- $\mathrm{HC}(\mathrm{OH})_{2}$ obtained and identified in the present work is presumably very reactive, and further reaction channels are of particular interest. For instance, these species may constitute new channels for the initiation and propagation of more complex organic species in the interstellar clouds. ${ }^{38}$ To our knowledge, the new reactions and species observed in the present work have not been considered in these interstellar processes. Another natural extension of this work is the study of reactions between atomic hydrogen and more complex molecules such as amino and fatty acids.

\section{Acknowledgements}

The work was supported by the Academy of Finland (Grant code 1139425) and the National Center for Research and Development of Poland (grant ERA-CHEMISTRY-2009/01/2010). The Wroclaw Center for Networking and Supercomputing and the CSC-IT Center for Science in Espoo are acknowledged for allocated computational resources.

\section{Notes and references}

1 W. E. Jones, S. D. Macknight and L. Teng, Chem. Rev., 1973, 73, 407-440.

2 J. Villà, A. González-Lafont, J. M. Lluch and D. G. Truhlar, J. Am. Chem. Soc., 1998, 120, 5559-5567.

3 J. P. Camden, H. A. Bechtel, D. J. Ankeny Brown, M. R. Martin, R. N. Zare, W. Hu, G. Lendvay, D. Troya and G. C. Schatz, J. Am. Chem. Soc., 2005, 127, 11898-11899.

4 R. B. Bohn, G. D. Brabson and L. Andrews, J. Phys. Chem., 1992, 96, 1582-1589.

5 M. Yamada and A. Amano, Ind. Eng. Chem. Res., 1992, 31, 8-13.

6 K. Hiraoka, A. Yamashita, T. Miyagoshi, N. Oohashi, Y. Kihara and K. Yamamoto, Astrophys. J., 1998, 508, 423-430.

7 S. E. Bisschop, G. W. Fuchs, E. F. van Dishoeck and H. Linnartz, Astron. Astrophys., 2007, 474, 1061-1071.

8 W. M. Garrison, W. Bennett, S. Cole, H. R. Haymond and B. M. Weeks, J. Am. Chem. Soc., 1955, 77, 2720-2727.

9 Q. Li, M. C. Osborne and I. W. M. Smith, Int. J. Chem. Kinet., 2000, 32, 85-91.

10 A. Miyoshi, H. Matsui and N. Washida, J. Chem. Phys., 1994, 100, 3532-3539.

11 G. S. Tyndall, T. J. Wallington and A. R. Potts, Chem. Phys. Lett., 1991, 186, 149-153.

12 M. Pettersson, J. Lundell, L. Khriachtchev and M. Räsänen, J. Am. Chem. Soc., 1997, 119, 11715-11716.

13 E. M. S. Maçôas, L. Khriachtchev, M. Pettersson, R. Fausto and M. Räsänen, J. Am. Chem. Soc., 2003, 125, 16188-16189.

14 E. M. S. Maçôas, L. Khriachtchev, M. Pettersson, R. Fausto and M. Räsänen, J. Phys. Chem. A, 2005, 109, 3617-3624.

15 S. Amiri, H. P. Reisenauer and P. R. Schreiner, J. Am. Chem. Soc., 2010, 132, 15902-15904.

16 L. Khriachtchev, A. Domanskaya, K. Marushkevich, M. Räsänen, B. Grigorenko, A. Ermilov, N. Andrijchenko and A. Nemukhin, J. Phys. Chem. A, 2009, 113, 8143-8146.

17 C. L. Hawkins and M. J. Davies, Biochim. Biophys. Acta, 2001, 1504, 196-219. 
18 F. Turecek and E. A. Syrstad, J. Am. Chem. Soc., 2003, 125, 3353-3369.

19 H. Tanskanen, L. Khriachtchev, M. Räsänen, V. I. Feldman, F. F. Sukhov, A. Yu. Orlov and D. A. Tyurin, J. Chem. Phys., 2005, 123, 064318.

20 M. Pettersson, J. Lundell, L. Khriachtchev and M. Räsänen, J. Chem. Phys., 1998, 109, 618.

21 M. Pettersson, L. Khriachtchev, S. Jolkkonen and M. Räsänen, J. Phys. Chem. A, 1999, 103, 9154-9162.

22 L. Khriachtchev, S. Tapio, A. Domanskaya, M. Räsänen, K. Isokoski and J. Lundell, J. Chem. Phys., 2011, 134, 124307.

23 E. Isoniemi, L. Khriachtchev, J. Lundell and M. Räsänen, Phys. Chem. Chem. Phys., 2002, 4, 1549-1554.

24 J. Lundell and M. Räsänen, J. Phys. Chem., 1995, 99, 14301-14308.

25 A. Domanskaya, K. Marushkevich, L. Khriachtchev and M. Räsänen, J. Chem. Phys., 2009, 130, 154509.

26 L. Khriachtchev, M. Saarelainen, M. Pettersson and M. Räsänen, J. Chem. Phys., 2003, 118, 6403-6410.

27 L. Khriachtchev, H. Tanskanen, A. Cohen, R. B. Gerber, J. Lundell, M. Pettersson, H. Kiljunen and M. Räsänen, J. Am. Chem. Soc., 2003, 125, 6876-6877.

28 Q. Cao, S. Berski, M. Räsänen, Z. Latajka and L. Khriachtchev, J. Phys. Chem. A, 2013, 117, 4385-4393.
29 J. Bernard, M. Seidl, I. Kohl, K. R. Liedl, E. Mayer, Ó. Gálvez, H. Grothe and T. Loerting, Angew. Chem., Int. Ed., 2011, 50, 1939-1943.

30 C. A. Wight and A. I. Boldyrev, J. Phys. Chem., 1995, 99, 12125-12130.

31 C. Lugez, A. Schriver, R. Levant and L. Schriver-Mazzuoli, Chem. Phys., 1994, 181, 129-146.

32 R. Tarroni, L. Khriachtchev, A. Domanskaya, M. Räsänen, E. Misochko and A. Akimov, Chem. Phys. Lett., 2010, 493, 220-224.

33 K. Marushkevich, L. Khriachtchev, M. Räsänen, M. Melavuori and J. Lundell, J. Phys. Chem. A, 2012, 116, 2101-2108.

34 V. I. Goldanskii, L. I. Trakhtenberg and V. N. Fleurov, Tunneling Phenomena in Chemical Physics, Gordon and Breach Science, New York, 1989.

35 L. Khriachtchev, J. Mol. Struct., 2008, 880, 14-22.

36 P. R. Schreiner, H. P. Reisenauer, D. Ley, D. Gerbig, C.-H. Wu and W. D. Allen, Science, 2011, 332, 1300-1303.

37 M. Pettersson, E. M. S. Maçôas, L. Khriachtchev, R. Fausto and M. Räsänen, J. Am. Chem. Soc., 2003, 125, 4058-4059.

38 A. G. G. M. Tielens and L. J. Allamandola, in Physics and Chemistry at Low Temperatures, ed. L. Khriachtchev, Pan Stanford Publishing, Singapore, 2011, pp. 341-380.

39 K. Marushkevich, M. Siltanen, M. Räsänen, L. Halonen and L. Khriachtchev, J. Phys. Chem. Lett., 2011, 2, 695-699. 